\title{
TARGETING OCCUPATIONS FOR DISPLACED WORKERS: A TEST IN WISCONSIN REGIONS
}

\author{
Eric Thompson and Ron Shaffer
}

\begin{abstract}
The regional portfolio variance technique and the National Industry-Occupation Employment Matrix are used to identify re-employment options for workers displaced during recession. The technique developed identifies sectors that create jobs during recession in occupations that displaced workers can fill quickly without substantial retraining or migration from the region. The compatibility between the occupations of displaced workers and the jobs created in growing sectors is based on the occupation-changing behavior observed in the Current Population Survey, January 1990, Special Survey of Displaced Workers. The sectors which created the most jobs compatible with the skills of a selected group of displaced workers tended to be in the workers' former major industry group, although sectors with compatible occupations were found in a wide variety of industries.
\end{abstract}

\section{INTRODUCTION}

Workers displaced from their jobs during recession face a difficult job search. With relatively few employers hiring, displaced workers compete for a limited number of job openings both in their own occupation and in occupations generally. Given these difficulties, many workers have faced bouts of long-term unemployment. During the last two recessions, more than a half million workers have joined the ranks of those unemployed for more than six months (Bureau of Labor Statistics 1981, 1983, 1989, 1991). Such bouts of unemployment have had a significant impact on the incomes of many displaced workers families, even after accounting for the income-smoothing effects of unemployment insurance and the earnings of other family members. A Congressional Budget Office (1990) study reported that the monthly poverty rate of displaced workers families rose from 9 percent before displacement to 19 percent after more than four months of unemployment.

Using the regional portfolio variance technique, this research identifies reemployment options for workers displaced during recession. The technique describes the contribution of individual sectors to the aggregate cyclical stability of the regional economy (Kurre and Weller 1989). Among the range of contribu-

\footnotetext{
Research Assistant Professor, Center for Business and Economic Research, Department of Economics, University of Kentucky; and Director, Center for Community Economic Development, and Professor, Department of Agricultural Economics, University of Wisconsin-Madison/Extension. The authors would like to thank the University of Wisconsin-Madison, College of Agricultural and Life Sciences Hatch Project No. 3208, for financial support. This revision benefited from the helpful comments of two anonymous referees.
} 
tions described, it points to some sectors which move counter to the regional business cycle.

Once these counter-cyclical sectors are identified, occupational data is used to identify which sectors create jobs during recession in occupations that displaced workers can fill quickly without substantial retraining or migration from the region. Such compatible occupations include a displaced workers previous occupation or an occupation the worker can switch into after displacement. This research accepts the occupation-switching behavior observed by displaced workers in the Current Population Survey, January 1990, Special Survey of Displaced Workers (Bureau of the Census 1990) as an indication of the occupational switching that is possible, since other data is not readily available. The likelihood of switching occupations is restrained by the reservation wages of displaced workers, the skill requirements in other occupations, and other sources of income available to the displaced such as unemployment insurance.

The method developed represents a new application for the portfolio variance technique. The technique has been used to describe the contribution of particular sectors to the instability of the aggregate regional economy. The method used here utilizes the portfolio variance technique, and the occupational structure of sectors, to describe the contribution of sectors to the re-employment prospects of a particular group of people-workers displaced from sectors that are shedding jobs. This use of the technique in part addresses the concern raised by Siegel, Alwang, and Johnson (1994) that the portfolio variance approach does not measure how the welfare of individual groups within an economy is influenced by changes in aggregate stability. ${ }^{1}$ From a policy perspective, displaced workers can be encouraged to seek work in counter-cyclical sectors which are creating jobs in compatible occupations. Information on these re-employment options is of use to unemployment offices and other agencies charged with helping the unemployed find work.

The portfolio variance technique is run in 14 multi-county Wisconsin regions. These regions are diverse, ranging from small nonmetropolitan tourism and forestry regions to large diversified metropolitan regions. By using the same level of sector disaggregation and the same regional concept in this diverse group of regions, this research makes two contributions to the application of the portfolio technique in nonmetropolitan places.

This research utilizes multi-county labor market areas as the unit of analysis for both nonmetropolitan and metropolitan regions. While previous applications of portfolio techniques in metropolitan areas have utilized the MSA concept (Conroy 1975; Kurre and Weller 1989), most previous applications in nonmetropolitan areas have used counties as the unit of analysis (Schoening and Sweeney 1989, 1992; and Brown and Pheasant 1985, 1987). However, Jackson 
(1984) is an exception. The use of counties has meant that these nonmetropolitan studies have failed to consider job opportunities for workers in adjacent counties (Tolbert and Killian 1987; and Jackson 1984).

This research also utilizes very disaggregate sector data both in nonmetropolitan and metropolitan Wisconsin regions. This is possible because the ES202 unemployment insurance program data that is used is available at the 3digit level for all counties. Use of ES202 data addresses concerns by Schoening and Sweeney (1989) that local data disclosure problems make it difficult to use the portfolio technique at a sufficiently disaggregate sector level to guide policy decisions in many small, nonmetropolitan places.

Literature on the portfolio variance technique and occupation switching is explored in Sections II and III of this paper. The research method is discussed in Section IV. Findings are discussed in Section V, and Section VI is a summary.

\section{PORTFOLIO VARIANCE MODELS}

Regional portfolio analysis is an adaptation of the expected growth and variance models developed for financial theory by Markowitz (1952). Such adaptations, which began with Conroy (1975), draw an analogy between sectors in a regional economy and financial assets in an investment portfolio. Employment or income growth in a sector is analogous to the money return from a stock investment. In regional portfolio analysis, the goal of regional stability is traded off with the goal of expected regional growth. A utility function based on expected growth and stability is maximized using a measure of risk-aversion to weight the growth and stability objectives. Alternatively, regional variance is minimized subject to a growth constraint (Lande 1994).

Some researchers have focused only on the stability of the regional portfolio rather than on both stability and growth (Kurre and Weller 1989). This portfolio variance approach is useful when regional stability is the issue of interest. It is used in this research because of a focus on the re-employment opportunities of workers displaced during recession. ${ }^{2}$

The regional portfolio variance is modeled as the weighted sum of the variance of employment in each sector in the region, $\sigma_{i}{ }^{2}$, and the covariance between sectors, $\sigma_{\mathrm{ij}}($ Conroy 1975):

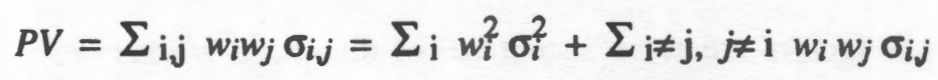


The weights $w_{i}$ and $w_{j}$ are sectors $i$ and j's share of regional employment. The values of a sectors covariance terms reflect whether the sector fluctuates with or counter to other sectors in the region. Sectors that fluctuate counter to other sectors in the region may even act to reduce the aggregate regional portfolio variance. The overall impact of a single sector $i$ on a region's aggregate portfolio variance is a weighted sum of its variance and covariances:

$$
\text { Impact }_{i}=\Sigma_{\mathrm{j}} w_{i} w_{j} \sigma_{\mathrm{ij}}=w_{i} *\left[\Sigma_{\mathrm{j}} w_{j} \sigma_{\mathrm{ij}}\right]
$$

Sectors for which that weighted sum is negative move counter to the regional economy. These sectors tend to grow faster as the regional economy grows slower, and vice versa. Many of these counter-cyclical sectors will even add jobs during recession. Sectors which do both-add jobs during recession and have a negative value for Equation 2-are focused on in this research.

Variance and covariance terms in previous studies have been derived either by taking the deviations of sector employment in each period from a time trend value or the sample mean, or by taking the deviations of growth in each period from mean growth in the sample (Schoening and Sweeney 1992). Variances and covariances are calculated here based on deviations from mean growth. Given growth, $g_{i t}$ in sector $i$ in period $t$, variances and covariances are calculated as follows (St. Louis 1980):

$$
\begin{array}{r}
\sigma_{1}^{2}=[1 /(T-1)] * \sum_{1}^{T}\left(g_{i t}-\bar{g}_{i}\right) \\
\sigma_{\mathrm{ij}}=[1 /(T-2)] * \Sigma_{1}^{\mathrm{T}}\left(g_{i t}-\bar{g}_{i}\right) *\left(g_{j t}-\bar{g}_{j}\right)
\end{array}
$$

Given previous findings that portfolio variance results using national data and more aggregate data do not match results using local data and less aggregate data, this study uses Wisconsin regional data at the three-digit SIC code level of aggregation to apply the portfolio variance technique (Schoening and Sweeney 1989; Brown and Pheasant 1985, 1987; and Jackson 1984). ${ }^{3}$

\section{OCCUPATIONAL COMPATIBILITY}

Wage and skill factors create an incentive for displaced workers to seek a new job in their previous occupation. After entering an occupation, workers can earn higher wages by accumulating occupation-specific human capital on the job (Lippman and McCall 1976). This encourages workers searching for a new job to 
remain in the same occupation, since these skills may not be valued in alternative occupations. Similarly, educational requirements in some occupations allow workers who have invested in a specialized education to earn higher wages in that occupation, but not in many others. To the degree that these occupation-specific factors allow workers to earn higher wages only in their own occupations, workers are less likely to switch.

The availability of other sources of income such as unemployment insurance or property income also reduces the incentive for displaced workers to change occupations. These alternative income sources reduce the urgency to find another job and allow time to search for work in the same or a similar occupation. To give an example, Stone (1980) estimated that workers receiving unemployment insurance were 19 percent less likely to search for work outside their former occupations.

Data on the occupation switching behavior of workers displaced during the 1985 to 1989 period are illustrated in Table 1, which summarizes data compiled from the Current Population Survey, January 1990, Special Survey of Displaced Workers (Bureau of the Census 1990). As part of that survey, workers who were displaced between 1985 and 1989 identified their current occupation as well as the occupation they held when displaced. The occupations were organized into the 35 occupational groups listed in Table 1. The "same occupational group" column in Table 1 shows what percentage of displaced workers from each occupational group were found to have their current jobs in the same occupational group. Table 1 also lists alternative occupational groups which workers switched into at least 5 percent of the time. Small proportions of workers moved into many other occupational groups. Table 1 lists only the more likely opportunities for occupation switching as defined by this 5 percent threshold.

Results in Table 1 confirm that workers do not voluntarily find new jobs in just any occupation but tend to concentrate in certain occupations. Displaced workers from nearly all occupational groups most frequently took new jobs in the same group, or in one or two related groups. ${ }^{4}$ This was particularly true in higher skill professional and technical occupations.

Data in Table 1 are supported by previous research. Bendick and Devine (1981) found that displaced workers from nationally declining occupations experienced a statistically significant increase in the length of their unemployment. This indicates that displaced workers do seek jobs in their previous occupations, and it is particularly true for workers in higher skill occupations. Rytina (1982), studying all workers who changed occupations, found that the likelihood of changing occupational groups was lowest in higher skill occupations such as professional, technical, and kindred workers. Similarly, Stone (1980) found a 
TABLE 1

Old And New Occupational Groups: Workers Displaced Between 1985 and 1989

\begin{tabular}{|c|c|c|c|}
\hline Old Occupational Group & $\begin{array}{l}\text { Same } \\
\text { cupational } \\
\text { Group }\end{array}$ & $\begin{array}{c}\text { First } \\
\text { Most Frequent } \\
\text { New Occupational Group } \\
\end{array}$ & $\begin{array}{c}\text { Second } \\
\text { Most Frequent } \\
\text { New Occupational Group } \\
\end{array}$ \\
\hline \multicolumn{4}{|l|}{ MANAGEMENT \& RELATED } \\
\hline Executives and Managers & $42 \%$ & Nonretail Sales(10\%) & Management Support(7\%) \\
\hline Management Support & $58 \%$ & Executives and Managers $(7 \%)$ & Other Admin. Support (7\%) \\
\hline \multicolumn{4}{|l|}{ PROFESSIONAL SPECIALTY } \\
\hline Engineers & $52 \%$ & Executives and Managers(13\%) & Math and Computer Sci.(6\%) \\
\hline Math and Computer Scientists & $59 \%$ & & \\
\hline Natural Scientists & $31 \%$ & & \\
\hline Health Diagnosing & $75 \%$ & & \\
\hline Health Assessment/Treating & $81 \%$ & & \\
\hline Teachers & $59 \%$ & & \\
\hline Lawyers and Judges & $86 \%$ & & \\
\hline Other Professionals & $60 \%$ & Executives and Managers $(8 \%)$ & \\
\hline \multicolumn{4}{|l|}{ TECHNICAL SPECIALTY } \\
\hline Health & $76 \%$ & & \\
\hline Engineering \& Science & $44 \%$ & Engineers(6\%) & Other Professional Spec.(6\%) \\
\hline Other Technical Specialties & $56 \%$ & Math \& Computer Scientists(7\%) & Executives and Managers(7\%) \\
\hline \multicolumn{4}{|l|}{ SALES } \\
\hline Non Retail Sales & $48 \%$ & Retail Sales(11\%) & Executives and Managers $(8 \%)$ \\
\hline Sales Workers, Retail & $45 \%$ & Food Service( $9 \%)$ & Other Admin. Support(9\%) \\
\hline \multicolumn{4}{|c|}{ ADMINISTRATIVE SUPPORT } \\
\hline Computer Equipment Operators & $39 \%$ & Executives and Managers(14\%) & Other Admin. Support(8\%) \\
\hline Secretaries & $53 \%$ & Other Admin. Support $(11 \%)$ & Financial/Man. Support(5\%) \\
\hline FinancialManagement Support & $41 \%$ & Other Admin. Support(18\%) & Executives and Managers $(8 \%)$ \\
\hline Mail and Message Distributing & $31 \%$ & Motor Vehicle Operator(23\%) & \\
\hline Other Administrative Support & $45 \%$ & Executives and Managers(11\%) & Retail Sales(6\%) \\
\hline \multicolumn{4}{|l|}{ SERVICES } \\
\hline Protective Services & $43 \%$ & Motor Vehicle Operator(12\%) & \\
\hline Food Service & $52 \%$ & Retail Sales(6\%) & Executives and Managers $(6 \%)$ \\
\hline Health Services & $59 \%$ & & \\
\hline Cleaning/Building Services & $46 \%$ & Machine Operators $(6 \%)$ & Motor Vehicle Operators $(6 \%)$ \\
\hline Personal Services & $51 \%$ & Retail Sales $(7 \%)$ & Food Service(6\%) \\
\hline \multicolumn{4}{|l|}{ PRECISION PRODUCTION } \\
\hline Mechanics & $53 \%$ & Construction Trade(5\%) & \\
\hline Construction Trades & $67 \%$ & Mechanic(5\%) & \\
\hline Other Precision Production & $44 \%$ & Machine Operators $(8 \%)$ & Mechanics(6\%) \\
\hline \multicolumn{4}{|c|}{ PRODUCTION OPERATIVES } \\
\hline Machine Operators and Tenders & $45 \%$ & Other Precision Production(5\%) & Fabricators and Assemb.(5\%) \\
\hline Fabricators and Assemblers & $42 \%$ & Machine Operators $(6 \%)$ & Construction Trades(6\%) \\
\hline Motor Vehicle Operators & $57 \%$ & Mechanics(5\%) & \\
\hline Other Transportation & $43 \%$ & Motor Vehicle Operators(10\%) & Machine Operators $(7 \%)$ \\
\hline Construction Laborers & $47 \%$ & Construction Trades $(8 \%)$ & Handlers, Cleaners, Lab.(7\%) \\
\hline Freight and Material Handlers & $29 \%$ & Fabricators and Assemb.(5\%) & Handlers, Cleaners, Lab.(5\%) \\
\hline Handlers, Cleaners, Laborers & $34 \%$ & Machine Operators(6\%) & Construction Trades $(6 \%)$ \\
\hline
\end{tabular}

Source: Compiled from Bureau of the Census, U.S. Department of Commerce, 1990. Current Population Survey, January 1990, Special Survey of Displaced Workers. Conducted by the Bureau of the Census for the Bureau of Labor Statistics. Diskettes available from the Bureau of Labor Statistics.

Note: Data on the most frequent new occupational group is presented only when the frequency of a switch was at least 5 percent. 
negative relationship between the willingness of displaced workers to switch occupations and wages earned in their previous job.

This finding of limited occupation switching by displaced workers implies that only some counter-cyclical sectors will create jobs in occupations compatible with the occupations of a particular group of displaced workers. The method described below is designed to identify those sectors that do so.

\section{METHOD AND DATA}

Analysis was conducted in 14 Wisconsin regions (Figure 1). The 14 study regions are based on multi-county labor market areas identified throughout the United States by Tolbert and Killian (1987). These multi-county regions encompass adjacent counties characterized by significant inter-county commuting. Thus these economic regions are designed to contain individuals facing a similar market for their labor. For this study, Tolbert and Killians (1987) Wisconsin labor market areas were adjusted to include all Wisconsin counties but no counties from adjacent states. ${ }^{5}$ The regions represent areas of very diverse size and industrial structure. The regions range in size from 9,712 jobs in Region 6 in 1981 to 483,166 jobs in Region $13 .^{6}$

Following Equation 2, each sector's impact on regional employment variance was calculated based on its employment variance and covariances, and its share of regional employment. Values were estimated from quarterly ES202 employment data from the first quarter of 1980 to the fourth quarter of $1989 .^{7}$ Data, which are available at the three-digit SIC code level of detail in all counties, were seasonally adjusted so that variance and covariance terms reflect cyclical but not seasonal variation. ${ }^{8}$ Weights were calculated from each sectors mean share of regional employment over the 1980 to 1989 period.

Sector variances and covariances were calculated initially based on data disaggregated to the three-digit SIC code level for sectors of all sizes. However, given concerns about potentially volatile growth rates in very small sectors, variances and covariances also were calculated when sectors with fewer than 100 jobs were combined. In one case, these smaller sectors were combined at the twodigit SIC level, in another case, at the one-digit SIC level. Sectors had to be identified as counter-cyclical under each of these three levels of aggregation in order to be considered counter-cyclical. Ninety percent of the sectors identified as counter-cyclical at the most disaggregate level were also identified as countercyclical in the cases where small sector data were aggregated to the two-digit or the one-digit level. 
FIGURE 1

The Fourteen Wisconsin Regions

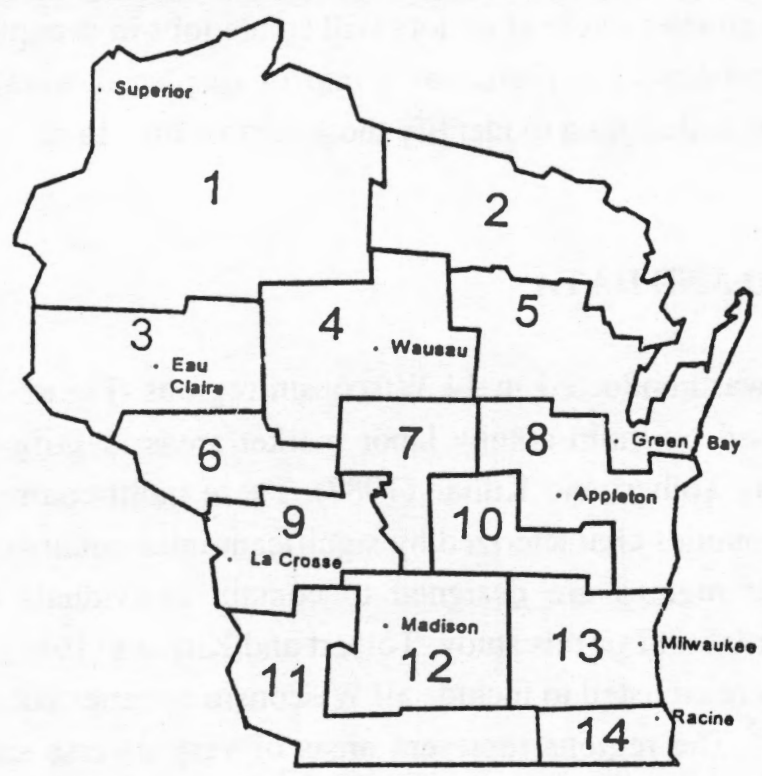

Counter-cyclical sectors had to have more than 100 jobs in at least one quarter. These sectors also had to add employment during the 1981-82 recession (from first quarter, 1981 through first quarter, 1983). ${ }^{9}$ The Wisconsin economy reached its cyclical peak in January 1981 and its cyclical trough in December 1982 (Nichols 1991). To avoid focusing on declining sectors, sectors also had to add employment over the 1980 to 1989 period.

Once counter-cyclical sectors were identified, their occupations were tested for compatibility with the occupations of workers displaced from sectors shedding employment. To test the proposed approach, this study looked at the occupations of jobs shed in the ten sectors in each region which lost the most jobs during the 1981-82 recession.

Testing for compatibility requires knowing the occupations of jobs shed or gained. Since this is not known at the firm and location level, an occupation's share of a local sector's job loss or gain was assumed to be equal to its share of national sector employment. ${ }^{10}$ The percentage of jobs in occupational groups within three-digit sectors were calculated from the 1990 values in the 1990-2005 National Industry-Occupation Employment Matrix (Bureau of Labor Statistics 1991). The matrix contains the amount of employment in more than 600 occupation categories in more than 300 sectors. This study aggregated the data to 35 occupational categories for the three-digit sectors, as shown in Table 1. For some sectors, employment data was omitted for certain occupations. While most sectors 
had less than 5 percent of employment in omitted occupations, some had more. Sectors with more than 20 percent of employment in omitted occupations were excluded from occupational analysis. Such sectors accounted for 20.7 percent of the counter-cyclical sectors identified.

The level of compatibility between occupations in a job-shedding sector and a counter-cyclical sector was determined by comparing the share of each sectors employment in the same occupational group, or in compatible occupational groups as defined using the same 5 percent threshold as in Table 1. For example, consider a job-shedding sector with 50 percent of its employment in the Executives and Managers occupational group and 50 percent in Math and Computer Scientists. Also, consider a counter-cyclical sector with 25 percent of its employment in Executives and Managers and 75 percent in Nonretail Sales. Start by comparing the degree to which jobs in the counter-cyclical sector are in the same occupational group as jobs in the job-shedding sector. The counter-cyclical sector has 25 percent of its employment in Executives and Managers, and no employment in Math and Computer Scientists. Thus 25 percent of the employment in the counter-cyclical and job-shedding sectors is in the same occupational group. Now examine how much of a match is possible once occupation switching is considered. According to Table 1, there is no occupational group frequently switched into by Math and Computer Scientists. Thus, there is no opportunity for a match of those jobs. However, Table 1 does indicate that Executives and Managers do frequently switch into Nonretail Sales. Nonretail Sales can be compatible for the remaining 25 percent of jobs in Executives and Managers. Thus, in total, 50 percent of the jobs in the counter-cyclical sector are occupationally compatible with jobs in the job-shedding sector.

\section{v. DISCUSSION}

The application of the portfolio technique in the 14 Wisconsin regions yielded 189 counter-cyclical sectors suitable for analysis. ${ }^{11}$ These counter-cyclical sectors on average generated 64.2 new jobs from the first quarter of 1981 to the first quarter of 1983 . This amounts to 9.6 percent of the total jobs lost by jobshedding sectors in regions during that time.

Results reported in Table 2 relate to the workers displaced from the ten sectors in each region which lost the most jobs during the 1981-1982 recession. The percentages reported reflect the average compatibility between the occupations of jobs generated in each counter-cyclical sector in a region and the occupations of the jobs shed in each of these top ten job-losing sectors. Compatibility was defined following the patterns in data shown in Table 1 from Current Population 
TABLE 2

Percent of Jobs in Counter-Cyclical Sectors Compatible with Occupations of Workers Displaced from the Top Ten Job-Shedding Sectors in Each Region

\begin{tabular}{lcc}
\hline \hline Region & Sectors & Percent \\
\hline 1 & 7 & 43.28 \\
2 & 8 & 41.96 \\
3 & 13 & 38.11 \\
4 & 11 & 47.77 \\
5 & 18 & 41.85 \\
6 & 3 & 43.04 \\
7 & 6 & 43.32 \\
8 & 23 & 42.16 \\
9 & 16 & 37.51 \\
10 & 12 & 46.43 \\
11 & 6 & 49.47 \\
12 & 22 & 44.69 \\
13 & 26 & 45.19 \\
14 & 18 & 36.97 \\
& & \\
Total & 189 & 42.59 \\
\hline
\end{tabular}

Survey, January 1990, Special Survey of Displaced Workers (Bureau of the Census 1990).

Using results from Region 1 as an example, 43.28 percent of the jobs in counter-cyclical sectors were occupationally compatible with the jobs in the ten largest job-shedding sectors in the region. Across all 14 regions, the average compatibility was 42.59 percent. $^{12}$ The regional average ranged from 36.97 percent in Region 14 to 49.47 percent in Region 11. These results indicate that on average, jobs in counter-cyclical sectors will be occupationally compatible with less than half of the jobs in job-shedding sectors. There are, however, groups of sectors for which compatibility is frequently higher.

Table 3 presents a list of the counter-cyclical sectors in each region which exceeded 50 percent compatibility with the ten largest job-shedding sectors. The lists in Table 3 indicate that in most regions, sectors in Manufacturing (SIC 2xx and $3 \times x$ ) most frequently had the highest levels of compatibility. This finding reflects that sectors from the same major industry group, or a closely related group, are more likely to have greater occupational compatibility. Since Manufacturing and Construction sectors were well represented among the top ten jobshedding sectors in the 14 regions (accounting for 63.6 percent), counter-cyclical Manufacturing sectors were well represented among the most compatible countercyclical sectors. In particular, in regions where most of the top ten jobs-shedding 


\section{TABLE 3}

Counter-Cyclical Sectors in Each Region with At Least 50 Percent of Jobs in Compatible Occupations Following Job-Switching Behavior in Current Population Survey Data

\begin{tabular}{lll}
\hline \hline & $\begin{array}{c}\text { Number Of Top } \\
\text { Ten Job-Shedding } \\
\text { Sectors In Manufacturing } \\
\text { \& Construction }\end{array}$ & \multicolumn{1}{c}{$\begin{array}{c}\text { Sectors With } 50 \text { Percent of Jobs } \\
\text { In Compatible Occupations }\end{array}$} \\
\hline Region & \multicolumn{1}{c}{$\begin{array}{l}\text { In } \\
1\end{array}$} & $202,384,503$ \\
2 & 7 & 394,481 \\
3 & 5 & $265,349,573,651$ \\
4 & 7 & $201,205,267,275,286,332,769$ \\
5 & 7 & $204,276,308,504,506,507$ \\
6 & 2 & 541 \\
7 & 4 & 273,518 \\
8 & 9 & $209,222,262,267,356,369,458$ \\
9 & 8 & $249,367,769$ \\
10 & 8 & $205,207,359,503,519$ \\
11 & 5 & $179,201,371$ \\
12 & 7 & $205,206,349,362,369,371,493,509,516,733$ \\
13 & 9 & $201,205,233,252,286,323,375,384,458$ \\
14 & 7 & $206,342,762$ \\
\hline
\end{tabular}

sectors were in Manufacturing or Construction (Regions 2, 4, 5, 8, 9, 10, 12, 13, and 14), most of the counter-cyclical sectors listed were in Manufacturing. By contrast, in Region 6, where only two of the top job-shedding sectors were in Manufacturing or Construction, a Retail Trade sector is listed.

But beyond these intuitive results, there are also additional counter-cyclical sectors with a high degree of compatibility with jobs lost in Manufacturing and Construction. Take again the example of Regions 2, 4, 5, 8, 9, 10, 12, 13, and 14. In these regions, sectors in Wholesale Trade (SIC 50x-51x), Miscellaneous Repair Services (76x), and Air Transportation, Communications and Utilities (SIC 45x, $48 x$, and $49 x$ ) were each found to have a high degree of compatibility with the workers displaced from the ten top job-shedding sectors. While in different major industry groups, these sectors had some occupational compatibility with Manufacturing and Construction sectors. The model identified these compatibilities. Wholesale sectors have a substantial share of employment in the Motor Vehicle Operators and Freight and Materials Handlers occupational groups, while Miscellaneous Repair Services and Air Transportation, Communications and Utilities have substantial employment in the Mechanics and the Other Precision Production occupational groups. The identification of these sectors shows how the model developed can identify counter-cyclical sectors with a substantial share of compatible occupations from a wide range of major industry groups. 
This result relied on the use of a 5 percent threshold for defining compatible occupational groups in data from the Special Survey of Displaced Workers, January 1990, Current Population Survey (Bureau of the Census 1990). As is seen in Table 1, many alternative occupational groups that were compatible under a 5 percent threshold would not be compatible at some higher threshold, such as 10 percent. Use of this higher threshold would reduce the compatibility of counter-cyclical sectors. In fact, if the same scenario is run under a 10 percent threshold, the average compatibility of Manufacturing sectors ( $2 x x-3 x x)$ falls by 9.4 percent, while compatibility falls 6.2 percent for Retail Trade sectors (52x59x), 4.7 percent for Services sectors ( $7 x x-8 x x), 6.1$ percent for Wholesale Trade sectors $(50 x-51 x), 16.0$ percent for Air Transportation, Communications and Utilities sectors (45x, 48x, and 49x), and 17.9 percent for Miscellaneous Repair Services sectors (76x). Thus, under this higher threshold, Manufacturing sectors would remain the most occupationally compatible. However, the compatibility of Air Transportation, Communications and Utilities sectors and Miscellaneous Repair Services sectors would drop substantially. The most compatible sectors would be more concentrated in Manufacturing.

\section{CONCLUSIONS}

This research developed a method to identify new job opportunities suitable for workers displaced by recession without requiring retraining or migration from the region. Counter-cyclical sectors which added jobs during recession were identified using the portfolio variance technique in $14 \mathrm{Wisconsin}$ regions. The occupations of jobs generated in these sectors were matched with those of displaced workers using the occupation switching behavior identified in the Current Population Survey, January 1990, Special Survey of Displaced Workers (Bureau of the Census 1990). This method represents a new application for the portfolio variance technique. It utilizes the portfolio model to describe the contribution of sectors to the re-employment prospects of a particular group of people-an occupationally specified group of displaced workers. The use of ES202 unemployment insurance data also makes it possible to examine disaggregate sectors in multicounty regions in nonmetropolitan as well as metropolitan places.

Analysis focused on the case of workers displaced from the ten sectors which lost the most jobs in each region during the 1981-1982 recession. In most regions, Manufacturing and Construction sectors accounted for most of these sectors. Following voluntary job switching patterns compiled from the Current Population Survey, it was found that on average 42.59 percent of the jobs generated in counter-cyclical sectors were compatible with the occupations of the workers dis- 
placed from these ten sectors. Counter-cyclical Manufacturing sectors were most often found to create a high share of jobs in compatible occupations, but sectors in Miscellaneous Repair Services (SIC 76x), Wholesale Trade (SIC 50x to 51x), and Air Transportation, Communications and Utilities (SIC 45x, 48x, and 49x) were also found to create a substantial share. Thus, the method developed identified counter-cyclical sectors with a high share of compatible occupations from a variety of major industry groups. However, the variety of compatible industries was reduced when the model was run under a stricter definition of compatibility.

Results in this research also were dependent on the level of aggregation chosen for occupational groups. Aggregation of over 600 occupational categories into 35 groups causes some imprecision in measurement of job switching rates. An occupational group which displaced workers are found to frequently switch into will contain some occupational subgroups that workers do not frequently choose. This could have caused the compatibility of occupational groups to be overstated. Bias also could have occurred due to the allocation assumption that was made. Job growth (loss) was allocated equiproportionally, with each occupational group receiving a share of job growth (loss) equal to its share of national employment in a sector. Alternative assumptions may have allocated more job growth into cyclically sensitive occupations such as production or sales workers. Such an allocation would likely have strengthened existing findings about how well Manufacturing, Wholesale Trade, Miscellaneous Repair Services, and Air Transportation, Communications and Utility sectors provided opportunities to workers displaced from Manufacturing and Construction sectors.

The results can be used to guide displaced workers to re-employment opportunities in growing counter-cyclical sectors. In particular, workers may be unaware of opportunities in sectors very different from the sector they were displaced from, as in the case of jobs in the Wholesale Trade sector for displaced Manufacturing and Construction workers. This information could be utilized by public and private placement services to give displaced workers additional ideas about sectors into which they can expand their job searches.

In addition, the method developed presents another way in which regional planners can analyze their economy to decide among alternative methods to aid workers displaced during recession. The method developed can provide insights into how well the occupations in a regions counter-cyclical sectors are compatible with the occupations of groups of displaced workers. The strength of that compatibility could help planners decide whether to put resources during recession into encouraging mobility between sectors and occupations, or to put resources into alternatives such as retraining or business attraction. 


\section{ENDNOTES}

1. Some groups do benefit from greater aggregate stability in the economy. These groups include local governments, owners of retail establishments, and property owners.

2. Sector growth is considered in this research, but not in the context of the optimal growth and stability trade-off as in the portfolio analysis model. Instead, there is simply a consideration of whether sectors grew from 1980 to 1989.

3. Sectors entering or exiting regions will be assigned missing values in the years before entry or after exit. Such sectors accounted for 2.7 percent of regional employment. Some three-digit sectors will have zero values in the middle of the time series. For these sectors, the growth rate will be undefined in the quarter when employment re-appears. Thus, such sectors will need to be combined together to create multiple sector series free of interior zero values. Sectors from the same two-digit SIC group will be combined, if possible. If not, sectors from the same one-digit SIC group will be combined. Such sectors with interior zero values accounted on average for 1.0 percent of employment in each region.

4. Some occupational groups had more than two alternative groups which were switched into at least 5 percent of the time. These were Executives and Managers, Retail Sales Workers, Financial and Management Support, Other Administrative Support, Personal Services, Other Precision Production, Fabricators and Assemblers, Other Transportation Operatives, Construction Laborers, and Freight and Materials Handlers.

5. Eight of the fourteen regions coincide exactly with Tolbert and Killian's (1987) regions. However, the remaining six do not. Since the ES202 data which was used was available only for Wisconsin, Regions 2,6 , and 9 do not include data for counties from neighboring states which belonged to these regions. Regions 1, 3, and 14 include data from additional Wisconsin counties which are part of adjacent labor market areas primarily located in neighboring states.

6. The amount of 1981 employment in the regions was: 46,304 in Region 1; 24,926 in Region 2; 56,689 in Region 3; 38,632 in Region 4; 80,588 in Region 5; 9,712 in Region 6; 29,189 in Region 7; 143,377 in Region 8; 48,550 in Region 9; 28,351 in Region 10; 24,904 in Region 11; 120,705 in Region 12; 483,166 in Region 13; and 114,128 in Region 14.

7. The ES202 unemployment insurance data set comes from the Wisconsin Department of Industry, Labor, and Human Relations. It contains data on establishment location by county, sector by four-digit SIC code, and employment by month. Thus the data are readily manipulated to obtain a quarterly 1980 to 1989 time-series of aggregate employment for three-digit SIC codes in counties. County data can then be aggregated into sub-state regions. Most state firms are 
covered in the ES202 data set. Covered firms are required by law to submit quarterly unemployment insurance information, so there are few missing data points. Wojan (1989) estimates that firms which account for 86 percent of Wisconsin employment participate in ES202. ES202 fails to cover some very small and family owned firms. It also sometimes assigns all multi-location firm employment to the headquarters, rather than to its actual location.

8. Calculations also run through a complete phase of the business cycle (Kurre and Weller 1989), from a year before the 1981-82 recession (first quarter, 1980) through before the 1990-91 recession (fourth quarter, 1989).

9. Counter-cyclical sectors consistently move counter to the aggregate economy. This implies growth during recession. Seventy percent of all countercyclical sectors added employment between first quarter 1981 and 1983.

10. Use of the national matrix is based on the assumption that national occupational patterns hold in Wisconsin regions. It also assumes that plants do not perform special functions, so that all plants have the industry-wide occupational breakdown.

11. These counter-cyclical sectors added jobs during the 1981-1982 recession, had more than 100 jobs, added employment between 1980 and 1989, and had less than 20 percent of their jobs suppressed in the 1990-2005 National Industry-Occupation Employment Matrix (Bureau of Labor Statistics 1991).

12. The lowest percentage of compatibility ( 32.54 percent) was found among sectors with at least 20 percent of jobs in Professional and Technical Specialty occupations.

\section{REFERENCES}

Bendick, M, Jr., and J.R. Devine. "Workers Dislocated by Economic Change: Do They Need Federal Employment and Training Assistance?" In Seventh Annual Report, The Federal Interest in Employment and Training, National Commission for Employment Policy, Washington, D.C. (October): 175-226, 1981.

Brown, Deborah J., and Jim Pheasant. "A Sharpe Portfolio Approach to Regional Economic Analysis." Journal of Regional Science 25(1985): 51-63. "Sources of Cyclical Employment Instability in Rural Counties." American Journal of Agricultural Economics 69(1987): 819-827.

Bureau of the Census, U.S. Department of Commerce. Current Population Survey, January 1990, Special Survey of Displaced Workers. Conducted by the Bureau of the Census for the Bureau of Labor Statistics. Diskettes available from the Bureau of Labor Statistics (1990). 
Bureau of Labor Statistics, U.S. Department of Labor. Employment and Earnings. Tables A-19 (1981) or A-17 (1983) or A-18 (1989 and 1991): Unemployed persons by occupation, industry, and duration of unemployment (July 1981, 1983, 1989, 1991).

Bureau of Labor Statistics, U.S. Department of Labor. 1990-2005 National Industry-Occupation Employment Matrix. Diskettes available from the Bureau of Labor Statistics (1991).

Congressional Budget Office. Family Incomes of Unemployment Insurance Recipients and the Implications for Extending Benefits. Washington, DC: Government Printing Office, 1991.

Conroy, Michael E. Regional Economic Growth: Diversification and Control. New York: Praeger, 1975.

Jackson, Randall W. "An Evaluation of Alternative Measures Of Regional Industrial Diversification." Regional Studies 18 (1984): 103-112.

Kurre, James A., and Barry R. Weller. "Regional Cyclical Instability: An Empirical Examination of Wage, Hours, and Employment Adjustments, and An Application of the Portfolio Variance Technique." Regional Studies 23 (1989): 315-329.

Lande, Paul S. "Regional Industrial Structure and Economic Growth and Instability." Journal of Regional Science 34 (1994): 343-360.

Lippman, Steven A., and John J. McCall. "The Economics of Job Search: A Survey (Part II)." Economic Inquiry 14 (1976): 347-368.

Markowitz, Harry M. "Portfolio Selection," Journal of Finance 7 (1952): 77-91.

Nichols, Donald A. The Wisconsin Economy In Recession. Madison, WI: Robert M. LaFollete Institute of Public Affairs, University of Wisconsin- Madison, 1991.

Rytina, Nancy F. "Occupational changes and tenure," Monthly Labor Review 105 (September 1982): 29-33.

St. Louis, Larry V. "A Measure of Regional Diversification And Efficiency," The Annals of Regional Science. 14 (1980): 21-30.

Schoening, Niles C., And Larry E. Sweeney. "Applying an Industrial Diversification Decision Model to Small Regions" The Review of Regional Studies. 19 (Winter 1989): 14-17.

. "Proactive Industrial Development Strategies and Portfolio Analysis." The Review of Regional Studies 22 (1992): 227-238.

Siegel, Paul B., Jeffrey Alwang, and Thomas G. Johnson. "Toward An Improved Portfolio Variance Measure of Regional Economic Stability." The Review of Regional Studies 24 (1994): 71-86.

Stone, Joe A. "Occupation Decisions of Unemployed Workers." In Unemployment Compensation Studies and Research (Volume 2). National Commission 
on Unemployment Compensation (July). Washington, DC: Government Printing Office, 1980.

Tolbert, Charles M. II, and Molly Sizer Killian. Labor Market Areas for The United States. Agricultural and Rural Economy Division, Economic Research Service, U.S. Department of Agriculture. Staff Report No. AGES870721, 1987.

Wojan, Tim. Reconciling Employment Estimates in Four Rural Wisconsin Counties. Unpublished: Department of Agricultural Economics, University of Wisconsin at Madison, 1989. 
- 